J. Clin. Chem. Clin. Biochom.

Vol. 25, 1987, pp. 799-804

(C) 1987 Walter de Gruyter \& Co.

Berlin - New York

\title{
An Enzyme Immunoassay for Phospholamban
}

\author{
By M. Holtzhauer \\ Central Institute for Cardiovascular Research, Academy of Sciences of the GDR, Berlin
}

(Reccived May 15/June 13, 1987)

\begin{abstract}
Summary: Phospholamban, a phosphorylatable protein of the cardiac sarcoplasmic reticulum, has been estimated by a semi-quantitative immunoassay. It can be determinated in purified membrane preparations as well as in crude fractions of cardiac muscle membranes, regardless of the phosphorylation state of the phosphoprotein. The content of phospholamban in mammalian heart muscle membrane vesicles correlates with the activity of the calcium/magnesium-dependent ATPase with the exception of the oxalate-loaded membrane preparations. This observation indicates that phospholamban and the calcium transporting enzyme are localized at different sites in cardiac sarcoplasmic reticulum.
\end{abstract}

\section{Introduction}

In 1972 Wollenberger (1) reported the presence of a phosphorylatable protein in a cardiac microsomal fraction. It was subsequently thoroughly investigated and named „phospholamban“ because it is an excellent substrate for cyclic AMP-dependent protein kinase $^{1}$ ) and, as reported later, also for a calcium/ calmodulin-dependent protein kinase (for review see 1.c. (2)). This protein phosphorylation is correlated with an alteration of the calcium transport activities of the heart sarcoplasmic reticulum. Phospholamban is believed to be a regulator protein of the calcium transport ATPase of this particular membrane system (3), but the mechanism of this interaction is not yet fully unterstood.

Phospholamban seems to be a heart-specific proteolipid. Different groups have described phospholamban" or a phospholamban-like protein as a constitutent of the sarcoplasmic reticulum and also of the sarcolemma of heart muscle cells $(4,5)$. However, the determination of the phospholamban content of these membrane systems is rather difficult, in as much as

\footnotetext{
1) Enzymes

$\mathrm{Ca}, \mathrm{Mg}$-dependent ATPase: EC 3.6.1.3

cyclic AMP-dependent protein kinase: EC 2.7.1.37
}

the proteolipid is weakly or not at all stainable in electrophoretic gels. Furthermore, protein determinations have given widely differing values for phospholamban, depending on the method used (6).

Based on its electrophoretically determined molecular weight and on the assumed 1:1 molar ratio of enzymatically incorporated ${ }^{32} \mathrm{P}$-labelled phosphoryl groups per polypeptide chain, quantification of phospholamban ranges from about 1 to 6 per cent by weight of the total membrane protein of the cardiac sarcoplasmic reticulum (7).

The development of an immunochemical assay should overcome some of these difficulties.

The aim of this paper is to describe the principle of a semi-quantitative enzyme immunoassay for phospholamban which was recently employed in a comparative study of the phorphorylation state of phospholamban in canine heart (8).

\section{Materials and Methods}

Horseradish peroxidasc (AWD Dresden) was purified on concanavalin A-Sepharosc. Goat anti-rabbit-IgG antibodies (SIfIN Berlin) were enriched by affinity chromatography on rabbit immunoglobulin-Sepharose. [ $\left.\gamma-{ }^{32} \mathrm{P}\right] \mathrm{ATP}$ (spec. radioactivity 180 $\mathrm{TBq} / \mathrm{mmol}$ ) was from ZfK Rossendorf (GDR). Nitrocellulose 
sheets were from Serva (Heidelberg), and polystyrene microtitre plates from VEB Polyplast Halberstadt (GDR). Freund's adjuvant was from IfI Dessau (GDR), and 3,3',4,4'-tetraaminodiphenylether was a gift from Dr. Ziebarth (ZIK Berlin).

Phospholamban was purified to electrophoretic homogeneity from porcine cardiac sarcoplasmic reticulum as described in l.c. (9). Heart sarcoplasmic reticulum was prepared according to Harigava \& Schurartz (10) with slight modifications. Highly purified heart sarcolemma was a gift of Dr. Vetter and was prepared as specified in 1.c. (11). Skeletal muscle sarcoplasmic reticulum from porcine diaphragm was prepared following the method given by 1.c. (12). Crude membrane fractions of different muscle types were isolated as described in 1.c. (8). Purified cardiac sarcoplasmic reticulum ("oxalate SR") was prepared as described in l.c. (13).

\section{Induction of antibodies}

Antibodies against purified phospholamban were produced in rabbits. Typically, a first immunization was performed by injection of $250 \mu \mathrm{g}$ of the purified protein in complete Freund's adjuvant/saline ( $1+1$ by volume) near to the popliteal lymph node. Booster injections were made six weeks later $(200 \mu \mathrm{g}$ in incomplete Freund's adjuvant/saline) and two weeks after the first booster by i. v. injection of a suspension of $170 \mu \mathrm{g}$ of phospholamban in saline. The development of antibody production was monitored by the described immunoassay.

\section{Enzyme-linked immunoassay}

For the development of the enzyme-linked immunoassay we followed the description of Douillard \& Hoffinan (14). Cardiac sarcoplasmic reticulum, other membrane preparations, and purified phospholamban were diluted in the binding buffer $(10$ $\mathrm{mmol} / \mathrm{l}$ sodium bicarbonate, $\mathrm{pH} \mathrm{9.6)} \mathrm{to} \mathrm{a} \mathrm{protein} \mathrm{concentration}$ of $25 \mathrm{mg} / \mathrm{l}$. A serial dilution of this solution $(200 \mu \mathrm{l})$ were pipetted into the wells of a microtitre plate. After incubation overnight at $4^{\circ} \mathrm{C}$ the plate was rinsed three times with phosphate-buffered saline, $\mathrm{pH} 7.4,1 \mathrm{~g} / 1$ gelatine, $0.5 \mathrm{~g} / \mathrm{l}$ Tween 20 . This was followed by the incubation of the bound protein with an appropriate dilution of the antiserum (usually $1: 1500$ ) or of normal control rabbit serum in phosphate-buffered saline, $\mathrm{pH} 7.4,1 \mathrm{~g} / 1$ gelatine, $0.5 \mathrm{~g} / 1$ Tween 20 for two hours at room temperature using a shaker. The unbound serum was washed out with phosphate-buffered saline, $\mathrm{pH} 7.4,1 \mathrm{~g} / 1$ gelatine, 0.5 $\mathrm{g} / \mathrm{l}$ Tween 20 and was replaced by $200 \mu \mathrm{l}$ of a $1: 2000$ dilution of the horseradish peroxidase-immunoglobulin conjugate in phosphate-buffered saline, $\mathrm{pH} 7.4,1 \mathrm{~g} / \mathrm{l}$ gelatine, $0.5 \mathrm{~g} / 1$ Tween 20 , and the plates were incubated for further two hours. The wells were rinsed again three times with phosphate-buffered saline, pH 7.4, $1 \mathrm{~g} / \mathrm{l}$ gelatine, $0.5 \mathrm{~g} / \mathrm{l}$ Tween 20 .

The peroxidase reaction was started by adding $200 \mu \mathrm{l}$ of the substrate buffer $(10 \mathrm{mg} o$-phenylenediamine and $10 \mu \mathrm{l} 300 \mathrm{~g} / \mathrm{kg}$ $\mathrm{H}_{2} \mathrm{O}_{2}$ per $100 \mathrm{ml}$ of $51.5 \mathrm{mmol} / \mathrm{l}$ disodium hydrogen phosphate, $33.8 \mathrm{mmol} / \mathrm{l}$ citric acid, $\mathrm{pH} 5.5$ ). The reaction was stopped 15 min later by addition of $60 \mu \mathrm{l}$ of $6 \mathrm{~mol} / \mathrm{l}$ sulphuric acid. The absorbance was measured in a multichannel spectrophotometer at $492 \mathrm{~nm}$ within 30 minutes.

\section{Electroblotting}

The specificity of the obtained antisera was checked by immunoblotting. Membrane proteins were separated in sodium dodecylsulphate-containing polyacrylamide gels (see below) then transfered onto nitrocellulose sheets by a modified version of the method of Khyse-Anderson (15). This modification consisted of the use of an additional sheet of filter paper soaked with 25 $\mathrm{mmol} / \mathrm{l}$ Tris-base, $40 \mathrm{mmol} / \mathrm{l} \varepsilon$-aminocaproic acid, and $0.5 \mathrm{~g} / \mathrm{l}$ sodium dodecylsulphate at the cathodic site of the electrophore- sis gel. Transfer was performed for $1.5 \mathrm{~h}$ at room temperature with $0.8 \mathrm{~mA}$ constant current per $\mathrm{cm}^{2}$ gel area.

After transfer the remaining active sites of the nitrocellulose were blocked in phosphate-buffered saline, $\mathrm{pH} \mathrm{7.4,1} \mathrm{g} / \mathrm{l}$ gelatine, $0.5 \mathrm{~g} / \mathrm{l}$ Tween 20 for 10 minutes. Incubation with the anti-phospholamban antiserum (dilution $1: 2000$ in phosphatebuffered saline, $\mathrm{pH} 7.4,1 \mathrm{~g} / 1$ gelatine, $0.5 \mathrm{~g} / 1$ Tween 20 was performed at $4{ }^{\circ} \mathrm{C}$ overnight, followed by three washes in phosphate-buffered saline, $\mathrm{pH} 7.4,1 \mathrm{~g} / 1$ gelatine, $0.5 \mathrm{~g} / \mathrm{l}$ Tween 20, incubation with a $1: 2000$ dilution of the peroxidase conjugate in phosphate-buffered saline, $\mathrm{pH} 7.4,1 \mathrm{~g} / \mathrm{l}$ gelatine, $0.5 \mathrm{~g} / \mathrm{l}$ Tween 20 , and the subsequent enzymatic reaction in phosphatebuffered saline with $3,3^{\prime}, 4,4^{\prime}$-tetraamino diphenylether and $\mathrm{H}_{2} \mathrm{O}_{2}$ as substrates.

\section{Miscellaneous methods}

Phosphorylation experiments in the presence of $\left[\gamma={ }^{32} \mathrm{P}\right] \mathrm{ATP}$ and the catalytic subunit of the cyclic AMP-dependent protein kinase were performed as described in 1.c. (9). The reaction was terminated either by a 50 -fold dilution of the reaction mixture with ice-cold stop buffer $(50 \mathrm{mmol} / \mathrm{l} \mathrm{KCl}, 5 \mathrm{mmol} / \mathrm{l}$ dithiothreitol, $10 \mathrm{mmol} / \mathrm{l}$ histidine, $\mathrm{pH}$ 6.8), by mixing with an equal volume of $150 \mathrm{~g} / 1$ trichloroacetic acid, or by adding the same volume of a solution of $150 \mathrm{~g} / \mathrm{l}$ of sulphosalicylic acid. The mixtures were centrifuged and the pellets were dissolved in the electrophoresis sample buffer $(50 \mathrm{mmol} / \mathrm{l}$ Tris $\mathrm{HCl}, \mathrm{pH}$ $6.8,50 \mathrm{~g} / 1$ sodium dodecylsulphate, $50 \mathrm{ml} / 1$ 2-mercaptoethanol) without further heating.

Sodium dodecylsulphate gel electrophoresis was run in the Laemmli system (16) with $\mathrm{T}=12.8 \%$ and $\mathrm{C}=5.0 \%$.

Autoradiographs were prepared using ORWO HS $11 \mathrm{X}$-ray films at $-78^{\circ} \mathrm{C}$. The autoradiographs and the blots were scanned on a Shimadzu CS-910 scanner (wavelength for the reaction product of the peroxidase reaction: 485 nm, for autora= diographs: $495 \mathrm{~nm}$ ).

The activity of the calcium/magnesium-dependent ATPase') was determined by a coupled optical assay according to l.c. (17). The conditions for the assay were (final concentrations, mmol/l): 80 histidine, $\mathrm{pH} 7.0,37^{\circ} \mathrm{C}, 100 \mathrm{KCl}, 5 \mathrm{NaN}_{3}, 4 \mathrm{MgCl}_{2}$, 2 ATP, 1 phosphoenolpyruvate, $0.2 \mathrm{NADH}, 0.1$ digitoxigenin, $10 \mathrm{mg} / \mathrm{l}$ pyruvate kinase, $10 \mathrm{mg} / \mathrm{l}$ lactate dehydrogenase, 1.5 $\mathrm{mg} / \mathrm{l}$ ionophore A 23187 in the presence or absence of $50 \mu \mathrm{mol} / \mathrm{l}$ $\mathrm{CaCl}_{2}$. The reaction was started by addition of the appropriate membrane vesicles ( 5 to $20 \mathrm{mg} / \mathrm{l}$ protein).

Protein was estimated by Lowry's method (18) with ovalbumin as standard.

\section{Results}

Below 5 to $10 \mu \mathrm{g}$ protein per well $(25$ to $50 \mathrm{mg} / \mathrm{l} ; 3$ to $6 \mu \mathrm{g} / \mathrm{cm}^{2}$ well surface) the quantity of protein was correlated with the absorbance of the peroxidase reaction product, i.e. within the binding capacity of the polystyrene microtitre plates. This correlation was verified for crude and purified porcine cardiac sarcoplasmic reticulum (fig. 1). A correlation also exists for the crude membrane fractions from rat and rabbit heart (fig. 1) and for purified phospholamban.

The specificity of the obtained antisera is shown by the electroblot of electrophoretically separated membrane proteins. Phospholamban was dedected 


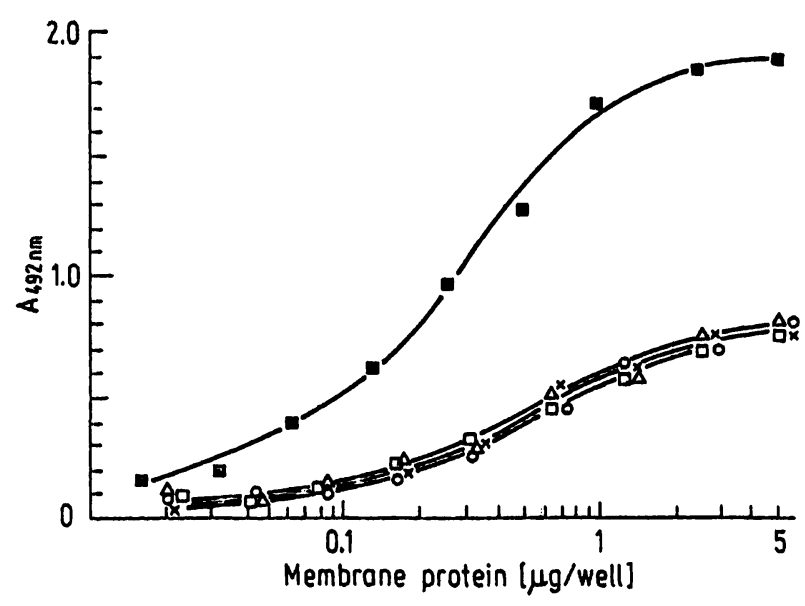

Fig. 1. Dose-response curve of the phospholamban enzyme immunoassay. The wells were coated with cardiac membrane preparations, followed by an incubation with antiphospholamban antisera (rabbit) and horseradish peroxidasc-anti-(rabbit-immunoglobulin)-IgG (goat) conjugate.

口- $\square$ sarcoplasmic reticulum (pig); $\square-\square$ crudc membranes (pig); $\Delta-\Delta$ crude membrancs (rabbit); $x-x$ crude membranes (rat).

For details see Material and Methods.

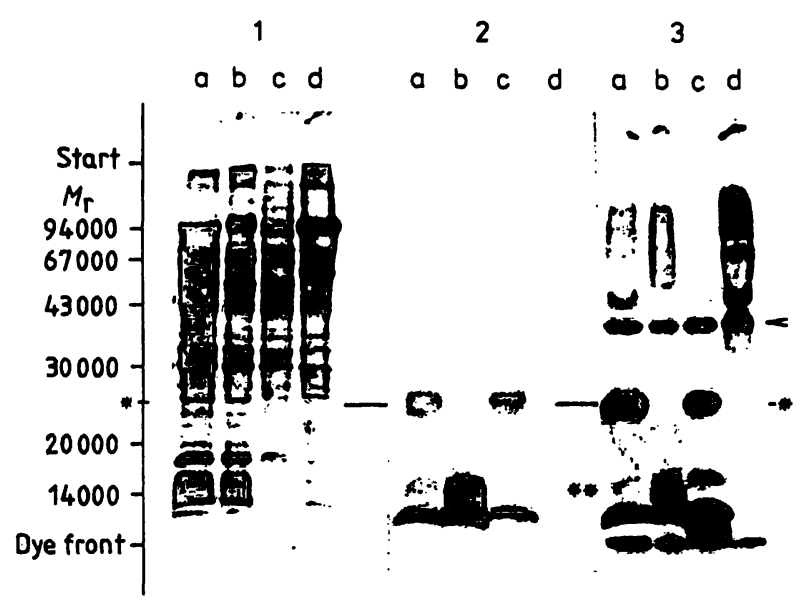

Fig. 2. Electropherogram, immunoblot, and autoradiogram of different membrane preparations.

1 - electropherogram (Coomassie brillant blue R250 staining),

2 - immunoblot,

3 - [ ${ }^{32}$ P]autoradiogram.

a - cardiac sarcoplasmic reticulum (pig);

$\mathrm{b}$ - the same as in a, boiled for $3 \mathrm{~min}$ prior to the electrophoresis;

c - cardiac sarcolemma (pig);

d' - skeletal sarcoplasmic reticulum (diaphragm, pig).

* - high molecular weight form of phospholamban $\left(M_{\mathrm{r}}\right.$ $=27000$ );

** - low molecular weight form of phospholamban.

by immunoblotting and by autoradiography. The immunostain of the electroblots and autoradiographs of the blots were compared with autoradiographs of ${ }^{32} \mathrm{P}$-labeled sarcoplasmic reticulum, separated by sodium dodecylsulphate polyacrylamide gel electrophoresis (fig. 2).
The phospholamban-bound ${ }^{32} \mathrm{P}$-radioactivity of the $M_{\mathrm{r}}=27000$ moiety (Fig. 1, lane $3 \mathrm{a}, \mathrm{c}$ and $2 \mathrm{a}, \mathrm{c}$, asterisk) and of the $M_{\mathrm{r}}=8000$ band and the immunostain were located in the same way.

Boiling of the vesicles of sarcoplasmic reticulum in electrophoresis sample buffer prior to electrophoresis shifted the high molecular weight form to the $M_{\mathrm{r}}=8000$ band in the immunostain as well as in the autoradiograph (fig. 2 , lanes $2 \mathrm{~b}$ and $3 \mathrm{~b}$ ). This low molecular weight form of phospholamban (indicated by two asterisks in fig. 2) is clearly different from the $M_{\mathrm{r}}=15000$ phosphoprotein of the cardiac sarcolemma, as indicated by its position in autoradiographs (fig. 2, lanes $3 \mathrm{c}$ and $2 \mathrm{c}$ ). There was no immunoreactivity on electroblots using skeletal muscle sarcoplasmic reticulum (fig. 2, lanes d).

The obtained polyspecific antibodies recognized subtypes of high molecular weight phospholamban both in the phosphorylated and in the non-phosphorylated state. Figure 3 shows the densitograms of immunoblots

a) of ${ }^{32} \mathrm{P}$-labeled, cyclic AMP-dependent phosphorylated phospholamban,

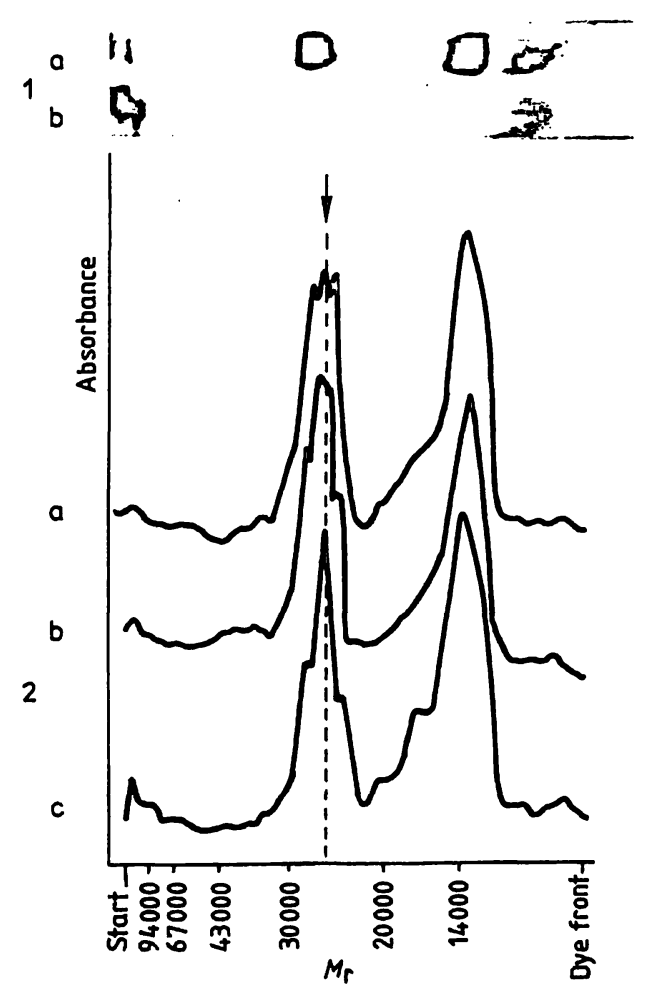

Fig. 3. Autoradiogram and densitogram of immunoblots.

1 - autoradiogram,

2 - densitogram of the immunoblot (arbitrary units).

a - phosphorylated, [32P]labeled sarcoplasmic reticulum;

b - the same as in a, treated with phosphatase S;

c - unphosphorylated sarcoplasmic reticulum.

Arrow and dotted line indicate the high molecular weight form of phospholamban $\left(M_{r}\right.$ ca. 27000). 
b) of the same preparation after phosphatase $S$ treatment (only the protein-bound ${ }^{32} \mathrm{P}$-phosphate groups were removed, whereas the ${ }^{32} \mathrm{P}$-label of the phospholipids at the dye front of the electropherogram was not influenced), and

c) of untreated vesicles of sarcoplasmic reticulum.

The arrow and the dotted line indicate the average value for the high molecular weight form of phospholamban $\left(M_{\mathrm{r}}=27000\right)$ and at least three different isoforms of the proteolipid. The different ratio of the peak height of these three subtypes could not significantly be correlated with a distinct status of phosphorylation.

Furthermore, the shapes of phospholamban bands on electropherograms differ, depending on the procedure by which the phosphorylation reaction was terminated. As shown in figure 4, the autoradiograph and especially the immunoblot gave different results after precipitation of membrane vesicles by

i) ice-cold trichloroacetic acid (fig. 4, lanes a),

ii) ice-cold sulphosalicylic acid (fig. 4, lanes b), or

iii) termination of the phosphorylation reaction by dilution, followed by high spin centrifugation.

The shape of the $M_{\mathrm{r}}=27000$ band was relatively constant, but the low molecular weight form smeared over a large area in i) and to a less extent in ii). The pictures obtained after dilution/centrifugation were most similar to those of purified phospholamban (fig. 4 , lanes $2 \mathrm{c}, 3 \mathrm{c}$ and $2 \mathrm{~d}, 3 \mathrm{~d}$ ). The peak height ratio of the $M_{\mathrm{r}}=27000$ to the $M_{\mathrm{r}}=8000$ to 12000 forms increased in the order a) to c) and the ratio of c) was also closest to that of purified phospholamban (fig. 4, lanes d). In contrast, the Coomassie stain (fig. 4, lanes $1 \mathrm{a}$ and $1 \mathrm{c}$ ) was only moderately influenced under these conditions.

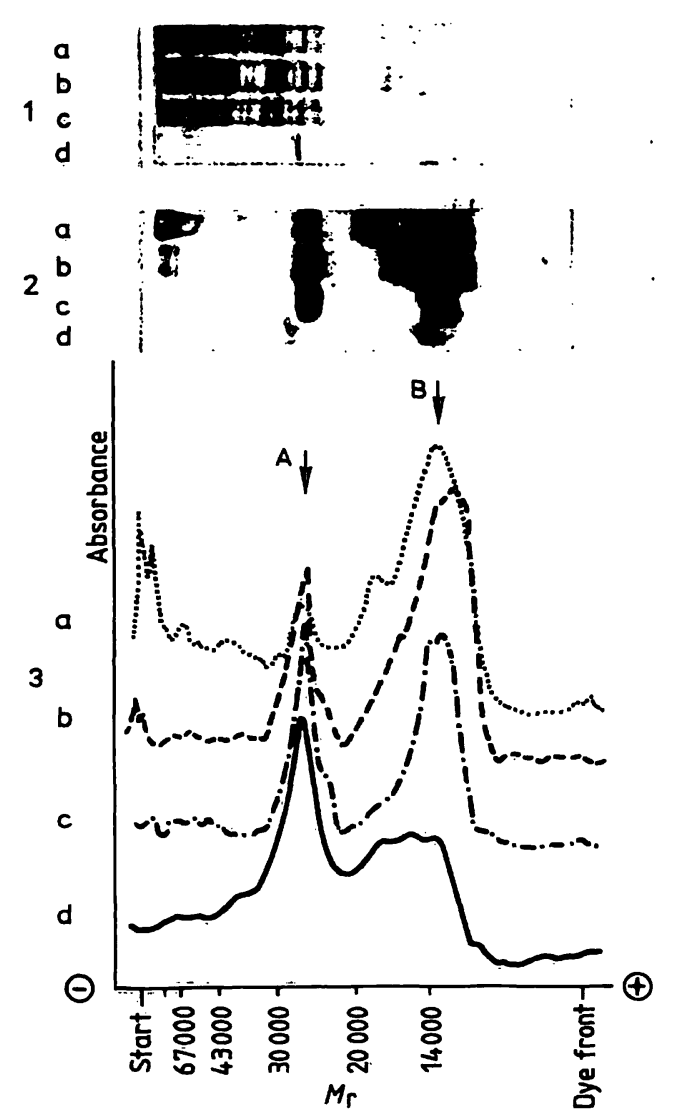

Fig. 4. Influence of the termination procedure of the phosphorylation reaction on the autoradiogram and immunoblot pattern.

1 - electropherogram (Coomassie brillant blue R250 staining),

$2-\left[{ }^{32}\right.$ P]autoradiogram,

3 - densitogram of the immunoblot (arbitrary units).

a - precipitation by trichloroacetic acid;

b - precipitation by sulphosalicyclic acid;

c - dilution and high speed centrifugation;

d - purified phospholamban.

A - high molecular weight form of phospholamban;

B - low molecular weight form.

For details see text.

Tab. 1. Relative content of phospholamban and calcium-dependent ATPase activity in different membrane preparations. Mean \pm S. D., number of independent estimations in parenthesis.

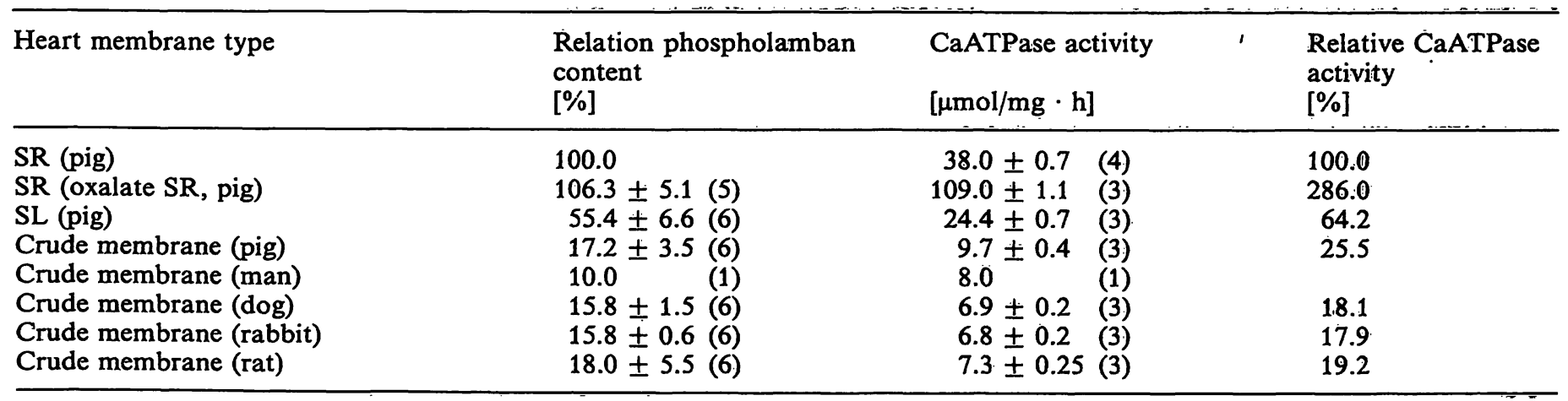

$\mathrm{SR}=$ sarcoplasmic reticulum,

$\mathrm{SL}=$ särcolemma 
The specifity of the antisera and the linearity of the solid-phase immunoassay provided an opportunity to determine the phospholamban content of membrane preparations from different sources.

As presented in table 1 , the relative content ${ }^{2}$ ) of phospholamban of different membrane samples (sacroplasmic reticulum, "oxalate SR" sarcoplasmic reticulum, sarcolemma, crude muscle membrane fractions) and of several species (dog, man, pig, rabbit, rat) was estimated and correlated with the calcium/ magnesium-dependent ATPase activity. In all cases, the phospholamban content corresponded to the enzyme activity, with the exception of the ATPaseenriched "oxalate SR" which showed a ratio of phospholamban content to enzyme activity of only one third.

\section{Discussion}

Phospholamban has been investigated for the last 15 years, but both its exact molecular structure and its function are still a matter of discussion. Determination of its molecular weight by sodium dodecylsulphate polyacrylamide gel electrophoresis gave values from $M_{\mathrm{r}}=20000-28000(2,6,19)$ for the high molecular weight form. Using the partial amino acid sequence published recently by Simmerman et al. (19) a $M_{\mathrm{r}}$ of about 5000 was calculated for the monomer and a pentamer is favored in their paper as the functional structure of phospholamban. The molecular weight calculated from the complete cDNAderived amino acid sequence as presented by 1.c. (20) is 6080 .

Phosphorylation of phospholamban by protein kinases results in an increase in the apparent molecular weight (21). The decrease in the relative electrophoretic mobility in the sodium dodecylsulphate polyacrylamide gel electrophoresis may be due to a lower content of sodium dodecylsulphate per molecule of the phosphorylated protein. This nonstoichiometric relation between phospholamban and the detergent may explain the unusual pattern of phospholamban in electropherograms in dependence on the anion (acid) used for the termination of the phosphorylation reaction (cf. fig. 4).

As demonstrated in 1.c. (19), each subunit of phospholamban has one phosphorylatable site for the

2) The relative content of phospholamban is defined as the absorbance of the horseradish peroxidase-immunoglobulin conjugate reaction product at $492 \mathrm{~nm}$ per $\mathrm{mg}$ of membrane protein related to the absorbance per $\mathrm{mg}$ of a standardized porcine cardiac sarcoplasmic reticulum preparation. cyclic AMP-dependent protein kinase and one for the calcium/calmodulin-dependent protein kinase(s). The quantification of phospholamban by measuring the in vitro incorporation of ${ }^{32} \mathrm{P}$-phosphate may be questionable, because a possible positive or negative cooperativity between the subunits during phosphorylation as well as the in vivo phosphorylation state of the protein are unknown, and dephosphorylation by phosphatase $S$ is accompanied by a loss of detectable phospholamban (8). Hitherto direct evidence for a steric hindrance of both phosphorylation sites is lacking, but this may arise if the phosphorylatable amino acids are neighbours (19).

For the absolute determination of the phospholamban content of a membrane preparation the exact determination of a purified preparation is necessary. The discrepency between the protein determination by Lowry's method and by dye binding protein assays (6) can be explained by the relative low content of aromatic amino acids in the molecule $(19,20)$. To overcome this problem we developed the described relative imrnunoassay which does not give the absolute value of the phospholamban content but makes it possible to compare the relative amounts of phospholamban in membrane preparations of different physiological states.

A remarkable observation in the present study was the discrepancy between the relative phospholamban content and the calcium/magnesium-dependent ATPase activity in oxalate-loaded sarcoplasmic reticulum vesicles (tab. 1). Whereas in all other membrane preparations the phospholamban content and the enzyme activity were in the same order of magnitude, in oxalate-loaded vesicles the amount of phospholamban was only a third with respect to the enzyme activity. This phenomenon can be explained by an enrichment of the calcium transporting enzyme during these specific preparation conditions and points to a different localization of phospholamban and calcium/magnesium-dependent ATPase within the sarcoplasmic membrane network.

The observed content of phospholamban in sarcolemmal preparations does not provide conclusive evidence concerning the presence of phospholamban in cardiac sarcolemma. So far, there is no further evidence that a phospholamban-like sarcolemmal proteolipid („calciductin“) exists in cardiac cells (cf. 1.c. (22), which could be immunochemically similar to phospholamban. Attemps the localize phospholamban ultrastructurally, however, favour its presence in the intracellular network ( $W$. Schulze \& $M$. Holtzhauer, unpublished). 
The polyclonal anti-phospholamban antiserum showed no species differences (fig. 1, tab. 1). The possibility of estimating phospholamban in crude membrane fractions of heart muscle opens the pros-

\section{References}

1. Wollenberger, A. (1972) Abstr. Invit. Present. Fifth Int. Congr. Pharmacol., $231-233$.

2. Tada, M. \& Inui, M. (1983) J. Molec. Cell. Cardiol. 15, $565-575$.

3. Le Peuch, C. J., Le Peuch, D. A. M. \& Demaille, J. G. (1980) Biochem. 19, 2268-3373.

4. Jones, L. R., Simmerman, H. K. B., Wilson, W. W., Gurd, F. R. N. \& Wegener, A. D. (1985) J. Biol. Chem. 260, $7721-7730$.

5. Lamers, J. M. J., De Jonge-Stintis, J. T., Huismann, W. \& Verdouw, P. D. (1986) J. Molec. Cell. Cardiol. 18, 115125.

6. Inui, M., Kadoma, M. \& Tada, M. (1985) J. Biol. Chem. $260,37-3715$.

7. Tada, M. \& Katz, A. M. (1982) Ann. Rev. Physiol. 44, $401-423$.

8. Karczewski, P., Vetter, R., Holtzhauer, M. \& Krause, E.G. (1986) Biomed. Biochim. Acta 45, S227-S231.

9. Holtzhauer, M., Sydow, H. \& Will, H. (1986) Biomed. Biochim. Acta 45, 719-725.

10. Harigaya, S. \& Schwartz, A. (1969) Circ. Res. $25,781-$ 794.

11. Vetter, R., Haase, H. \& Will, H. (1982) FEBS Lett. 148, $326-330$. pect of a semi-quantitative determination of phospholamban in biopsies of different animals. It is hoped to achieve this aim in a follow-up investigation.

12. Nelson, T. E. (1983) J. Clin. İnvest. 72், 862-870.

13. Levitsky, D. O., Aliev, M. K., Kusmin, A. V., Levchenko, T. S., Smirnov, V. N. \& Chazov, E. J. (1976) Biochim. Biophys. Acta 443, 468-484.

14. Douillard, J. Y. \& Hoffman, T. (1983) in Meth. Enzymol. (Langone, J. J. \& van Vunakis, H., eds.) 92, 168-174, Academic Press, New York.

15. Khyse-Anderson, J. (1984) Biochem. Biophys. Meth. 10, $203-209$.

16. Laemmli, U. K. (1970) Nature 227, 680-685.

17. Leonards, K. S. \& Kutchai, H. (1985) Biochemistry 24, 4876-4882.

18. Lowry, O. H., Rosebrough, N. J., Farr, A. L. \& Randall, J. (1951) J. Biol. Chem. 193, 265-275.

19. Simmerman, H. K. B., Collins, J. H., Theibert, J. L., Wegener, A. D. \& Jones, L. R. (1986) J. Biol. Chem. 261, $13333-13341$.

20. Fujii, J., Ueno, A., Kitano, K., Tanaka, S., Kadoma, M. \& Tada, M. (1987) J. Clin. Invest. 79, $301-304$.

21. Imagawa, T., Watanabe, T. \& Nakamura, T. (1986) J. Biochem. 99, 41-53.

22. Katz, A. M., Colvin, R. A. \& Ashavaid, T. (1983) J. Molec. Cell. Cardiol. 15, 795-797.

Dr. Martin Holzhauer

Akademie der Wissenschaften

Zentralinst. f. Herz- u.

Kreislauf-Forschung

R.-Rössle-Straße 10

DDR-1115 Berlin-Buch 